\title{
Biochemical characterization of the class B acid phosphatase (AphA) of Escherichia coli MG1655
}

\author{
Claudio Passariello ${ }^{\mathrm{a}, 1}$, Costantino Forleo ${ }^{\mathrm{b}, \mathrm{c}, 1}$, Vanna Micheli ${ }^{\mathrm{b}}$, Serena Schippa ${ }^{\mathrm{a}}$, Rosalida Leone ${ }^{\mathrm{c}}$, \\ Stefano Mangani ${ }^{\mathrm{c}}$, Maria Cristina Thaller ${ }^{\mathrm{d}}$, Gian Maria Rossolini ${ }^{\mathrm{b}, *}$ \\ a Dipartimento di Scienze di Sanità Pubblica, Università di Roma "La Sapienza", 00185 Rome, Italy \\ ${ }^{\mathrm{b}}$ Dipartimento di Biologia Molecolare, Sezione di Microbiologia, Università degli Studi di Siena, Policlinico Santa Maria alle Scotte, 53100 Siena, Italy \\ c Dipartimento di Chimica, Università di Siena, 53100 Siena, Italy \\ ' Dipartimento di Biologia, Università di Roma "Tor Vergata", 00133 Rome, Italy
}

Received 13 October 2004; received in revised form 19 August 2005; accepted 23 August 2005

Available online 2 November 2005

\begin{abstract}
The AphA enzyme of Escherichia coli, a molecular class B periplasmic phosphatase that belongs to the DDDD superfamily of phosphohydrolases, was purified and subjected to biochemical characterization. Kinetic analysis with several substrates revealed that the enzyme essentially behaves as a broad-spectrum nucleotidase highly active on $3^{\prime}$ - and $5^{\prime}$-mononucleotides and monodeoxynucleotides, but not active on cyclic nucleotides, or nucleotides di- and triphosphate. Mononucleotides are degraded to nucleosides, and AphA apparently does not exhibit any nucleotide phosphomutase activity. However, it can transphosphorylate nucleosides in the presence of phosphate donors. Kinetic properties of AphA are consistent with structural data, and suggest a role for the hydrophobic pocket present in the active site crevice, made by residues Phe 56, Leu71, Trp77 and Tyr193, in conferring preferential substrate specificity by accommodating compounds with aromatic rings. AphA was inhibited by several chelating agents, including EDTA, EGTA, 1,10-phenanthroline and dipicolinic acid, with EDTA being apparently the most powerful inhibitor. (C) 2005 Elsevier B.V. All rights reserved.
\end{abstract}

Keywords: AphA; class B acid phosphatase; Escherichia coli; Kinetic analysis; Biochemical characterization

\section{Introduction}

The Escherichia coli AphA protein (AphA_ECOLI, swissprot accession: P32697) is a molecular class B bacterial phosphatase that belongs to the DDDD superfamily of phosphohydrolases [1]. AphA is an oligomeric protein made of four identical $25-\mathrm{kDa}$ subunits that is secreted in the periplasmic space. The enzyme exhibits optimal activity at acidic $\mathrm{pH}$ values and requires a metal co-factor for activity, as suggested by susceptibility to inhibition by EDTA [2] and by crystallographic data [3].

Preliminary functional characterization showed that the enzyme is able to dephosphorylate various organic phosphomonoesters, including $5^{\prime}$ - and $3^{\prime}$-mononucleotides, $2^{\prime}$-deoxy-5'mononucleotides, aryl-phosphates and glycerol 2-phosphate,

\footnotetext{
* Corresponding author. Tel.: +39 0577 233327; fax: +39 0577233870 .

E-mail address: rossolini@unisi.it (G.M. Rossolini).

${ }^{1}$ Equally contributed to this work.
}

being also able to catalyze the transfer of phosphate from $p$ nitrophenyl phosphate ( $p$ NPP) to hydroxyl groups of other organic compounds [2].

The crystal structure of the AphA enzyme has been recently solved [3], revealing that, despite the lack of sequence homology, AphA exhibits a haloacid dehalogenase fold similar to that of other phosphatases such as the phosphoserine phosphatase (PSP) of Methanococcus jannaschii (PDB: 1F5S) $[3,4]$, and the human mitochondrial $5^{\prime}-\left(3^{\prime}\right)$-deoxyribonucleotidase (dNT-2) (PDB: 1MH9) [3,5].

In this work, we report a biochemical characterization of the AphA enzyme and discuss some functional features of the enzyme in relation to the protein three-dimensional structure.

\section{Materials and methods}

\subsection{AphA production and purification}

The AphA enzyme was produced in E. coli DH5 $\alpha$ (pATac) essentially as described previously [6]. The enzyme was extracted from cells grown 
aerobically at $37{ }^{\circ} \mathrm{C}$ in Super Broth [7] supplemented with $45 \mathrm{mM}$ potassium phosphate buffer $\mathrm{pH} 7.2$ and ampicillin $(250 \mu \mathrm{g} / \mathrm{ml})$ for plasmid selection. The culture was induced with isopropyl- $\beta$-D-thiogalactopyranoside (IPTG) ( $0.5 \mathrm{mM}$ final concentration) when $A_{600}$ reached a value of 0.5 . Cells were collected by centrifugation $\left(15,000 \times g\right.$ for $45 \mathrm{~min}$ at $\left.4{ }^{\circ} \mathrm{C}\right) 15 \mathrm{~h}$ after induction, and the enzyme was extracted from the periplasmic space as described previously [2]. The enzyme was precipitated from the periplasmic extract by adding $30 \%(\mathrm{w} / \mathrm{v})$ PEG6000. The precipitate was removed by centrifugation $\left(15,000 \times g\right.$ for $40 \mathrm{~min}$ at $\left.4{ }^{\circ} \mathrm{C}\right)$, the pellet was solubilized in buffer A (10 mM Tris- $\mathrm{HCl} \mathrm{pH} 7.45,1 \mathrm{mM} \mathrm{MgCl} 2$; approximately $1 / 50$ of the original culture volume) and, after centrifugation $(15,000 \times \mathrm{g}$ for $40 \mathrm{~min}$ at $4{ }^{\circ} \mathrm{C}$ ), the cleared supernatant was loaded (flow rate, $2 \mathrm{ml} / \mathrm{min}$ ) onto a DEAESepharose FF column $(1.6 \mathrm{~cm}$ by $20 \mathrm{~cm}, 35 \mathrm{ml}$ of bed volume, AmershamPharmacia Biotech, Milan, Italy) equilibrated with buffer A. The flowthrough fractions, containing the enzymatic activity, were concentrated approximately 7-fold by ultrafiltration, using a Centriprep YM-30 device (Millipore, Billerica, Massachusetts, USA). The concentrated enzyme preparation was diluted 1:10 in buffer B (10 mM MES- $\mathrm{NaOH} \mathrm{pH} 6.0,1 \mathrm{mM} \mathrm{MgCl}_{2}, 1 \%$ (w/ v) PEG 6000), and loaded (flow rate, $2 \mathrm{ml} / \mathrm{min}$ ) onto a Source $15 \mathrm{~S}$ column $(1.6 \mathrm{~cm}$ by $5 \mathrm{~cm}, 10 \mathrm{ml}$ of bed volume, Amersham-Pharmacia Biotech) equilibrated with the same solution. The bound enzyme was eluted with a linear $\mathrm{NaCl}$ gradient $(0-0.8 \mathrm{M})$ in the same buffer. Fractions containing phosphatase activity, eluted at $300 \mathrm{mM} \mathrm{NaCl}$, were pooled, and concentrated by ultrafiltration using a Centricon YM-10 device (Millipore) to a final concentration of $6 \mathrm{mg} / \mathrm{ml}$. At this stage, the enzyme preparation was $>99 \%$ pure, as determined by SDS-PAGE. All chromatography steps were carried out a room temperature (approximately $20^{\circ} \mathrm{C}$ ).

\subsection{Enzyme assays}

\subsubsection{Phosphatase assay during AphA purification}

Phosphatase assay was performed in $20 \mathrm{mM}$ sodium acetate buffer, $1 \mathrm{mM}$ $\mathrm{MgCl}_{2} \mathrm{pH} 6$ (assay buffer), at $37^{\circ} \mathrm{C}$, using as substrate $1 \mathrm{mM} p \mathrm{NPP}$, in a volume of $250 \mu$. The reaction was stopped after $5 \mathrm{~min}$ of incubation by addition of 750 $\mu \mathrm{l}$ of $2 \mathrm{~N} \mathrm{NaOH}$. Cleavage of $p$ NPP was determined by measurement of the released $p$-nitrophenol $(p \mathrm{NP})$ at $414 \mathrm{~nm}\left(\varepsilon=18,000 \mathrm{M}^{-1} \times \mathrm{cm}^{-1}\right)$.

\subsubsection{HPLC assay of phosphatase and phosphotransferase activity of AphA}

HPLC was used to identify and quantitate substrates and products in phosphatase and phosphotransferase assays as follows. Assays were carried out in assay buffer (see above), for $10 \mathrm{~min}$ at $37^{\circ} \mathrm{C}$, in a final volume of 250 $\mu \mathrm{l}$. Reactions were stopped by adding $3 \mathrm{M}$ perchloric acid $(30 \mu \mathrm{l})$; precipitated proteins were spun down by centrifugation at $14,000 \times g$ for 3 min, and the supernatant was brought to neutral $\mathrm{pH}$ with $3.5 \mathrm{M} \mathrm{K}_{2} \mathrm{CO}_{3}$; the precipitated perchlorate was removed by centrifugation, and the cleared supernatants were processed using an HPLC apparatus (Beckman System Gold Module 126, with a mod. 167 dual channel scanning detector module; Beckman Coulter inc. Fullerton, CA, USA) equipped with either a Supelcosil LC-18 column (Beckman, $3 \mu \mathrm{m}$ particle size, $75 \times 4.6 \mathrm{~mm}$ ) or an ODS Ultrasphere column (Beckman, $3 \mu \mathrm{m}$ particle size, $70 \times 4.6 \mathrm{~mm}$ ), and Supelguard columns (Beckman; $5 \mu \mathrm{m}, 2 \mathrm{~cm}$ ). The elution pattern used a gradient of eluant A $(0.1 \mathrm{M}$ potassium phosphate buffer, $6 \mathrm{mM}$ tetrabutylammonium phosphate, $\mathrm{pH} 5.5$ or 6 ) and eluant $\mathrm{B}$ (methanol), as follows: isocratic phase at $5 \%$ of eluant B for $5 \mathrm{~min}$, then increase to $20 \%$ eluant B in $1 \mathrm{~min}$, then holding for $6 \mathrm{~min}$, then increase to $30 \%$ eluant $\mathrm{B}$, and finally back to the initial conditions after 2 min. Initial conditions were restored in $8 \mathrm{~min}$, and total run time was $22 \mathrm{~min}$. The HPLC procedures were always performed at room temperature (approximately $20^{\circ} \mathrm{C}$ ). The flow rate was 1 $\mathrm{ml} / \mathrm{min}$. The absorbance was monitored at 260 and $280 \mathrm{~nm}$. Peak identities were confirmed by retention time, coelution with added internal standards, and the 260/280 $\mathrm{nm}$ absorbance ratios, as described previously [8]. Concentration/area linear plots were developed for quantification using System Gold Chromatography software ver. 3.10 (Beckman). A mixture of all standard solutions was injected daily to check the reliability of separation and any modification of retention times due to the chromatographic system. Zero-time blanks were performed for each assay. In phosphotransferase assays, either $p$ NPP or nucleotides were used as phosphate donors, and various nucleoside compounds as acceptors.

\subsubsection{Assays for inhibition by chelators}

Inhibition by chelators was assayed by calculating the chelator concentration that caused a decrease of $50 \%$ of AphA activity $\left(\mathrm{IC}_{50}\right)$, after incubation of the purified AphA enzyme (16.8 nM considering the monomer) with variable concentrations of each chelator, for $30 \mathrm{~min}$ at $37^{\circ} \mathrm{C}$, in assay buffer (see above) with no $\mathrm{MgCl}_{2}$ added. Residual enzyme activity was measured essentially as described above (point 2.2.1), by addition of $p$ NPP ( $2 \mathrm{mM}$ final concentration) as substrate (in absence of $\mathrm{MgCl}_{2}$ ), allowing a reaction time of $7 \mathrm{~min}$. A control assay with no chelators added was always run in parallel.

\subsection{Determination of the AphA kinetic parameters}

The steady-state kinetic parameters $\left(K_{\mathrm{M}}\right.$ and $\left.k_{\text {cat }}\right)$ of purified AphA were determined by measuring phosphatase activity under initial rate conditions using the Hanes-Woolf plot for linearization of the Michaelis-Menten equation [9]. Enzyme assays were always performed in assay buffer (see above) at $37^{\circ} \mathrm{C}$. In these experiments, the phosphatase activity was assayed by measuring the released inorganic phosphate $(\mathrm{Pi})$ detected by the acidified ammonium molybdate method [10] at $820 \mathrm{~nm}\left(\varepsilon=14,000 \mathrm{M}^{-1} \times \mathrm{cm}^{-1}\right)$. When the $K_{\mathrm{M}}$ values were lower than $80 \mu \mathrm{M}$, they were measured again as inhibition constants $\left(K_{\mathrm{i}} \mathrm{S}\right)$ in a competitive model, using $p \mathrm{NPP}$ as the reporter substrate, and reading the released $p \mathrm{NP}$ at $414 \mathrm{~nm}$ after blocking the reaction with $2 \mathrm{M} \mathrm{NaOH}$. In preliminary experiments, the amount of $p$ NP measured by absorbance at $414 \mathrm{~nm}$ was found to be equivalent to that of Pi measured by the acidified ammonium molybdate method under the above experimental conditions. The $K_{\mathrm{i}}$ value was determined by the plot of $V_{\mathrm{o}} / V_{\mathrm{i}}$ versus [I], yielding a line whose slope is $K_{\mathrm{M}}^{\mathrm{S}} /$ $\left(K_{\mathrm{M}}^{\mathrm{S}}+[S]\right) \times K_{\mathrm{i}}$, where $V_{\mathrm{o}}$ and $V_{\mathrm{i}}$ are the initial rates of $p$ NPP hydrolysis in the absence and presence of the inhibitor, respectively, $[I]$ is the inhibitor concentration, $[S]$ is the reporter substrate concentration, and $K_{\mathrm{M}}^{\mathrm{S}}$ the Michaelis constant of the enzyme for the reporter substrate. The enzyme assays for measurement of kinetic parameters were carried out in a volume of $0.3 \mathrm{ml}$ (the final volume after blocking the reaction with acidified ammonium molybdate or with $2 \mathrm{M} \mathrm{NaOH}$ was $1 \mathrm{ml}$ ) for $5 \mathrm{~min}$ at $37^{\circ} \mathrm{C}$. The enzyme concentration used in the assays was $14.2 \mathrm{nM}$ (considering the monomer).

\subsection{Computational studies}

All docking calculations were performed using the AutoDock 3.0.5 software package [11,12].

The AphA class B acid phosphatase/phophotransferase (AphA) atomic coordinates used in the docking studies were derived from the structure of the native AphA refined at $1.7 \AA$, filed in the Brookhaven Protein Data Bank (PDB) (PDB entry code $1 \mathrm{~N} 8 \mathrm{~N}$ ). All calculations were performed on one monomer of the protein (chain A). All crystallographic water molecules were removed from $1 \mathrm{~N} 8 \mathrm{~N}$ to create the initial coordinates for the simulations, with the exception of the molecules labeled as $\mathrm{HOH} 15$ and $\mathrm{HOH} 17$, which were considered in all calculations. Both water molecules are located into the binding site, near the catalytic $\operatorname{Mg}(\mathrm{II})$ ion, in a position where they might assist the binding of the ligands. The Autodock Tools (ADT) package was employed to generate the docking input files and to analyze docking results. AMBER united atom types were assigned to the protein using the program ADT. Kollmann charges were loaded for the protein, while Gasteiger charges were used for the ligands, for the water molecules HOH882 and HOH857 and for phosphate ion. A charge +2 and a fragmental volume of 2.66 cubic $\AA$ were assigned to $\mathrm{Mg}(\mathrm{II})$. A grid box size of $80 \times 80 \times 80$ points with a spacing of $0.270 \AA$ between the grid points was used. The grid was centred on the mass center of the ligand. Two hundred and fifty docked structures were generated using hybrid genetic algorithm-local search (GA-LS). A protocol with an initial population of 100 randomly placed individuals, a maximum number of 300,000 energy evaluation, and a maximum number of 100,000 generations was applied. A mutation rate of 0.02 and a crossover rate of 0.8 were used. Results differing by less than $2.0 \AA$ in positional root-mean-square deviation (RMSD) were clustered together and represented by the result with the most favorable free energy of binding. The docking analyses were performed on the following different complexes: AphA plus 5'-dAMP; AphA plus 5'-dCMP; AphA plus 5'AMP; AphA plus 5'-CMP; and AphA plus ATP. The lowest-energy individual from more populated clusters [13], found inside an energy window of $1.5 \mathrm{kcal} /$ mol from the energetic minimum, were analyzed. 


\subsection{Chemicals}

All chemicals were from Sigma Aldrich (St. Louis, MO, USA) unless otherwise specified.

\section{Results}

\subsection{Kinetic parameters of AphA with organic phosphoesters}

Kinetic parameters of AphA $\left(K_{\mathrm{M}}\right.$ and $\left.k_{\text {cat }}\right)$ were determined with several organic phosphoesters under initial rate conditions. Results of these experiments confirmed that AphA is active on several phosphomonoesters, but not on $3^{\prime}, 5^{\prime}$-cAMP, ADP or ATP. Overall, the $3^{\prime}$-mononucleotides and $3^{\prime}$-monodeoxynucleotides appeared to be the best substrates $\left(k_{\mathrm{cat}} / K_{\mathrm{M}}\right.$ ratios $\left.>10^{7} \mathrm{M}^{-1} \times \mathrm{s}^{-1}\right)$. Also the $5^{\prime}$-mononucleotides and $5^{\prime}$ monodeoxynucleotides appeared to behave as very good substrates $\left(k_{\text {cat }} / K_{\mathrm{M}}\right.$ ratios $>10^{6} \mathrm{M}^{-1} \times \mathrm{s}^{-1}$ and, with $5^{\prime}$-dAMP, $\left.k_{\text {cat }} / K_{\mathrm{M}}>10^{7} \mathrm{M}^{-1} \times \mathrm{s}^{-1}\right)$, with the notable exception of $5^{\prime}-$ CMP and $5^{\prime}$-dCMP $\left(k_{\text {cat }} / K_{\mathrm{M}}\right.$ ratios $\left.<10^{6} \mathrm{M}^{-1} \times \mathrm{s}^{-1}\right)$. In the latter cases, the drop in catalytic efficiency was due to higher $K_{\mathrm{M}}$ values, compared to those observed with other mononucleotides. The enzyme exhibited a good activity also with $p$ NPP $\left(k_{\text {cat }} / K_{\mathrm{M}}\right.$ ratio, around $\left.10^{6} \mathrm{M}^{-1} \times \mathrm{s}^{-1}\right)$, for which an overall lower affinity than that observed with most mononucleotides $\left(K_{\mathrm{M}}, 169 \mu \mathrm{M}\right)$ is compensated by a higher turnover rate. Sugar-phosphates and $\beta$-glycerol-phosphate appeared to be poor substrates, due a combination of low affinity and low turnover rates (Table 1).

\subsection{Reaction products with nucleotides}

Reaction products generated by AphA from different nucleotide substrates were investigated by HPLC analysis. With $3^{\prime}$ - and $5^{\prime}$-mononucleotides, results always revealed the presence of the corresponding nucleoside species (Table 2). Additional molecular species (such as nucleotides phosphorylated at different positions) were not detectable indicating that, under the assay conditions adopted for these experiments, the enzyme does not exhibit any significant nucleotide phosphomutase activity. No dephosphorylating activity was observed with NADP or GTP (Table 2).

\subsection{Phosphotransferase activity of AphA}

Phosphotransferase activity of AphA was investigated using either $p$ NPP, $3^{\prime}$-UMP or $5^{\prime}$-UMP as phosphate donors and various nucleoside compounds as acceptors, and analyzing the reaction products by HPLC. Results of these experiments showed that AphA is capable of transferring phosphate from either $p$ NPP or UMP to adenosine or uridine (Table 3 ). With adenosine, the molecular species generated by the transphosphorylation reaction included $5^{\prime}$-AMP, $3^{\prime}$-AMP and $3^{\prime}, 5^{\prime}$-ADP, while with uridine, only the $3^{\prime}$ - or $5^{\prime}$-monophosphorylated species were observed (Table 3). With NAD, ADPR or NAM as acceptors phosphotransferase activity from $p$ NPP was not detectable (Table 3).
Table 1

Kinetic parameters of the AphA protein with several organic phosphoesters

\begin{tabular}{|c|c|c|c|}
\hline Substrate & $K_{\mathrm{M}}(\mu \mathrm{M})^{\mathrm{a}}$ & $k_{\text {cat }}\left(\mathrm{s}^{-1}\right)$ & $k_{\text {cat }} / K_{\mathrm{M}}\left(\mathrm{M}^{-1} \times \mathrm{s}^{-1}\right)$ \\
\hline 5'-AMP & 3.0 & 23 & $7.6 \times 10^{6}$ \\
\hline $5^{\prime}-\mathrm{GMP}$ & 15 & 65 & $4.3 \times 10^{6}$ \\
\hline 5'-UMP & 15 & 61 & $4.1 \times 10^{6}$ \\
\hline 5'-CMP & 138 & 26 & $1.9 \times 10^{5}$ \\
\hline $3^{\prime}-\mathrm{AMP}$ & 0.9 & 33 & $4.1 \times 10^{7}$ \\
\hline 3'-GMP & 1.7 & 39 & $2.3 \times 10^{7}$ \\
\hline 3'-UMP & 1.2 & 61 & $5.1 \times 10^{7}$ \\
\hline $3^{\prime}-\mathrm{CMP}$ & 9.0 & 91 & $1.0 \times 10^{7}$ \\
\hline $5^{\prime}$-dAMP & 0.8 & 14 & $1.8 \times 10^{7}$ \\
\hline $5^{\prime}$-dGMP & 3.0 & 15 & $5.0 \times 10^{6}$ \\
\hline $5^{\prime}$-dUMP & 10 & 24 & $2.4 \times 10^{6}$ \\
\hline $5^{\prime}-\mathrm{dCMP}$ & 35 & 26 & $7.4 \times 10^{5}$ \\
\hline $3^{\prime}-\mathrm{dAMP}$ & 1.5 & 27 & $1.8 \times 10^{7}$ \\
\hline $3^{\prime}-\mathrm{dGMP}$ & 1.6 & 26 & $1.6 \times 10^{7}$ \\
\hline 3'-dUMP & 0.9 & 29 & $3.2 \times 10^{7}$ \\
\hline $3^{\prime}-\mathrm{dCMP}$ & 1.3 & 101 & $7.7 \times 10^{7}$ \\
\hline$p$ NPP & 169 & 156 & $9.2 \times 10^{5}$ \\
\hline Ribose-5-P & 980 & 4.9 & $5.0 \times 10^{3}$ \\
\hline Glucose-6-P & 1288 & 10 & $7.8 \times 10^{3}$ \\
\hline$\beta$-Glycerol-P & 666 & 2.9 & $4.3 \times 10^{3}$ \\
\hline $3^{\prime}, 5^{\prime}$-cAMP & $\mathrm{ND}^{\mathrm{b}}$ & $\mathrm{NH}^{\mathrm{c}}$ & ND \\
\hline ATP & $\mathrm{ND}^{\mathrm{b}}$ & $\mathrm{NH}^{\mathrm{c}}$ & ND \\
\hline ADP & $\mathrm{ND}^{\mathrm{b}}$ & $\mathrm{NH}^{\mathrm{c}}$ & ND \\
\hline
\end{tabular}

Data are mean values of three independent measurements. Standard deviations for $K_{\mathrm{M}}$ and $k_{\text {cat }}$ values were always lower than $10 \%$.

${ }^{\text {a }}$ Determined as $K_{\mathrm{i}}$ when, in the direct assay, $K_{\mathrm{M}}$ was lower than $80 \mu \mathrm{M}$.

${ }^{\mathrm{b}} \mathrm{ND}$, not determined.

c $\mathrm{NH}$, no hydrolysis was detected incubating an enzyme concentration of $14.2 \mathrm{nM}$ (considering the monomer) with substrate concentrations up to 0.5 $\mathrm{mM}$ in a final volume of $0.3 \mathrm{ml}$, for $5 \mathrm{~min}$, at $37^{\circ} \mathrm{C}$.

\subsection{Inhibition of AphA by divalent ion chelators}

Inhibition of AphA by divalent ions chelators was investigated by measuring the $\mathrm{IC}_{50}$ of various chelators on phosphatase activity. The strongest inhibitory activity was observed with EDTA $\left(\mathrm{IC}_{50}, 0.4 \mu \mathrm{M}\right)$, while 1,10-phenanthroline, EGTA, and dipicolinic acid exhibited lower inhibitory activities $\left(\mathrm{IC}_{50}\right.$, 2.0, 2.5 and $2.5 \mu \mathrm{M}$, respectively).

\subsection{Modelling of substrates in the AphA active site}

The high resolution X-ray structure of AphA was used to test possible binding modes of nucleotide substrates to the enzyme active site by docking analysis, and to correlate the results with the experimentally measured thermodynamic parameters. Fig. 1 shows the structure of AphA with the active site residues possibly involved with substrate binding highlighted.

AphA-5'-dAMP interaction: three similarly populated clusters of conformers were found showing three quite different binding modes. The lowest-energy cluster consists of $5^{\prime}$-dAMP molecules oriented into the active site with an oxygen atom of the phosphate moiety bound to $\mathrm{Mg}$ (II), the distance between two atoms being $2.27 \AA$. The phosphate group is involved in a network of hydrogen bonds with the $\mathrm{N} \varepsilon$ atom of the Lys 152 side chain, with the backbone NH of Gly113 and with the hydroxyl group of the Thr112 side chain. The nucleotide 
Table 2

Reaction products generated by AphA following hydrolysis of some nucleotide substrates

\begin{tabular}{lcl}
\hline Substrate (mM) & ${\text { Phosphatase } \text { activity }^{\mathrm{a}}}$ & Products \\
\hline 5'-AMP (0.5) & 3.9 & Adenosine, Pi \\
5'-AMP (5) & 3.9 & Adenosine, Pi \\
5'-UMP (0.5) & 4.6 & Uridine, Pi \\
5'-GMP (5) & 3.9 & Guanosine, Pi \\
5'-CMP (5) & 13.7 & Cytidine, Pi \\
5'-IMP (5) & 13.1 & Inosine, Pi \\
3'-AMP (5) & 23.4 & Adenosine, Pi \\
3'-UMP (0.5) & 6.3 & Uridine, Pi \\
Succinyl-AMP (0.2) & 2.6 & Succinyl-adenosine, Pi \\
NADP (5) & 0 & - \\
GTP (5) & 0 & - \\
\hline
\end{tabular}

Data on phosphatase activity are mean values of three independent measurements. Standard deviations were always lower than $10 \%$.

a Activity is expressed in $\mu$ moles of dephosphorylated product $/ \mathrm{min} / \mathrm{nmole}$ of enzyme.

aromatic ring shows a very good fit into the lipophylic pocket defined by Phe56 and Tyr193, while ring the amino group is hydrogen bonded to the side chains of the residues Thr192 and Ser53 (Fig. 2A). In the other two clusters, the phosphate moiety is positioned into the metal binding site in a way that resembles the aforementioned conformer. In this case, the 5'-dAMP purinic ring is surrounded by residues Tyr193, Glu68, Tyr70 and Leu71 and does not show a perfect $\pi-\pi$ interaction with the aromatic rings of the Tyr193 and Phe56 as in the previous cluster.

AphA-5'-AMP interaction: the three lower-energy clusters are the most populated and contain a similar number of individuals. In all three cases, a phosphate oxygen is coordinated to the $\operatorname{Mg}(\mathrm{II})$ ion. The first and the second clusters show lowest-energy conformers with the phosphate moiety Hbonded to $\mathrm{N} \varepsilon$ of the Lys152 and to the backbone $\mathrm{NH}$ of Gly113. The three conformers differ in the orientation of the purinic ring. In the first cluster, the ring shows a very good fit into the lipophylic pocket defined by Phe56 and Tyr193 and the ring amino group interacts with the side chain of residues Thr192 and Tyr70. In the second cluster, the purinic moiety is located into the lipophylic pocket and the amino group points toward the protein core, surrounded by residues Ser191 and Ser53. In the third cluster the purinic moiety is not perfectly aligned to the aromatic rings of residues Phe56 and Tyr193 and the amino group points toward the solvent-exposed area of the protein.

AphA $-5^{\prime}$-dCMP interaction: two highly populated lowenergy clusters were found. The lowest-energy and mostpopulated cluster shows one of the phosphate oxygens of $5^{\prime}$ dCMP coordinated to the $\mathrm{Mg}(\mathrm{II})$ ion, while the remaining oxygens interact with the $\mathrm{N} \varepsilon$ of the Lys152 and with the backbone NH of Gly113. In the second cluster, a comparable interaction of the phosphate moiety was found. The lowestenergy individuals from two clusters differ in the orientation of the pirimidinic ring: in the first cluster the ring lays outside of the lipophylic pocket defined by residues Phe56 and Tyr193, the ring amino group interacts with the side chain of residue Ser115 and the carbonyl group is involved in a hydrogen bond with the backbone NH of Arg114. In the second cluster, the ring fits in the pocket defined by the aromatic rings of Tyr193 and Phe56 (Fig. 2B).

AphA-5'-CMP interaction: two high populated clusters were found. The lowest-energy and most-populated cluster shows one phosphate oxygen coordinated to the $\mathrm{Mg}(\mathrm{II})$ and the remaining oxygens of the phosphate group are involved in a

Table 3

Phosphotransferase activity of AphA using different phosphate donors and nucleoside acceptors

\begin{tabular}{|c|c|c|c|c|}
\hline Phosphate donor (mM) & Phosphate acceptor (mM) & 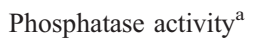 & Phosphotransferase activity ${ }^{\mathrm{a}}$ & Reaction products $^{\mathrm{b}}$ \\
\hline$p$ NPP (5) & NAD $(0.5)$ & 21.3 & $\mathrm{ND}^{\mathrm{c}}$ & ND \\
\hline$p$ NPP (5) & NAD (5) & 2.3 & ND & ND \\
\hline$p$ NPP (5) & $\operatorname{ADPR}^{\mathrm{d}}(0.5)$ & 19.6 & ND & ND \\
\hline$p$ NPP (5) & $\mathrm{NMN}^{\mathrm{e}}(1)$ & 43.2 & ND & ND \\
\hline \multirow[t]{3}{*}{$p \mathrm{NPP}(2)$} & Adenosine $(0.1)$ & 10.7 & 0.18 & 5'-AMP \\
\hline & & & 0.09 & $3^{\prime}-\mathrm{AMP}$ \\
\hline & & & 0.05 & $3^{\prime}, 5^{\prime}-\mathrm{ADP}$ \\
\hline \multirow[t]{3}{*}{$p$ NPP (5) } & Adenosine (1) & 0.7 & 0.82 & 5'-AMP \\
\hline & & & 0.64 & 3'-AMP \\
\hline & & & 0.73 & $3^{\prime}, 5^{\prime}-\mathrm{ADP}$ \\
\hline \multirow[t]{2}{*}{$p$ NPP (2) } & Uridine $(0.1)$ & 9.7 & 0.73 & $5^{\prime}$-UMP \\
\hline & & & 1.18 & 3'-UMP \\
\hline \multirow[t]{3}{*}{$3^{\prime}$-UMP $(0.5)$} & Adenosine $(0.5)$ & 3.9 & 0.27 & 5'-AMP \\
\hline & & & 0.82 & 3'-AMP \\
\hline & & & 0.82 & $3^{\prime}, 5^{\prime}-\mathrm{ADP}$ \\
\hline \multirow[t]{3}{*}{$5^{\prime}$-UMP $(0.5)$} & Adenosine $(0.5)$ & 4.2 & 0.07 & $5^{\prime}-\mathrm{AMP}$ \\
\hline & & & 0.05 & 3'-AMP \\
\hline & & & 0.05 & $3^{\prime}, 5^{\prime}-\mathrm{ADP}$ \\
\hline
\end{tabular}

Data on phosphatase and phosphotransferase activities are mean values of three independent measurements. Standard deviations were always lower than $15 \%$.

${ }^{\text {a }}$ Activities are expressed in $\mu$ moles of dephosphorylated or transphosphorylated product $/ \mathrm{min} / \mathrm{nmole}$ of enzyme.

b $p$ NP or Uridine resulting from dephosphorylation of the phosphate donor are not reported.

c ND, not detectable.

d ADP-ribose.

e Nicotinamide-mononucleotide. 


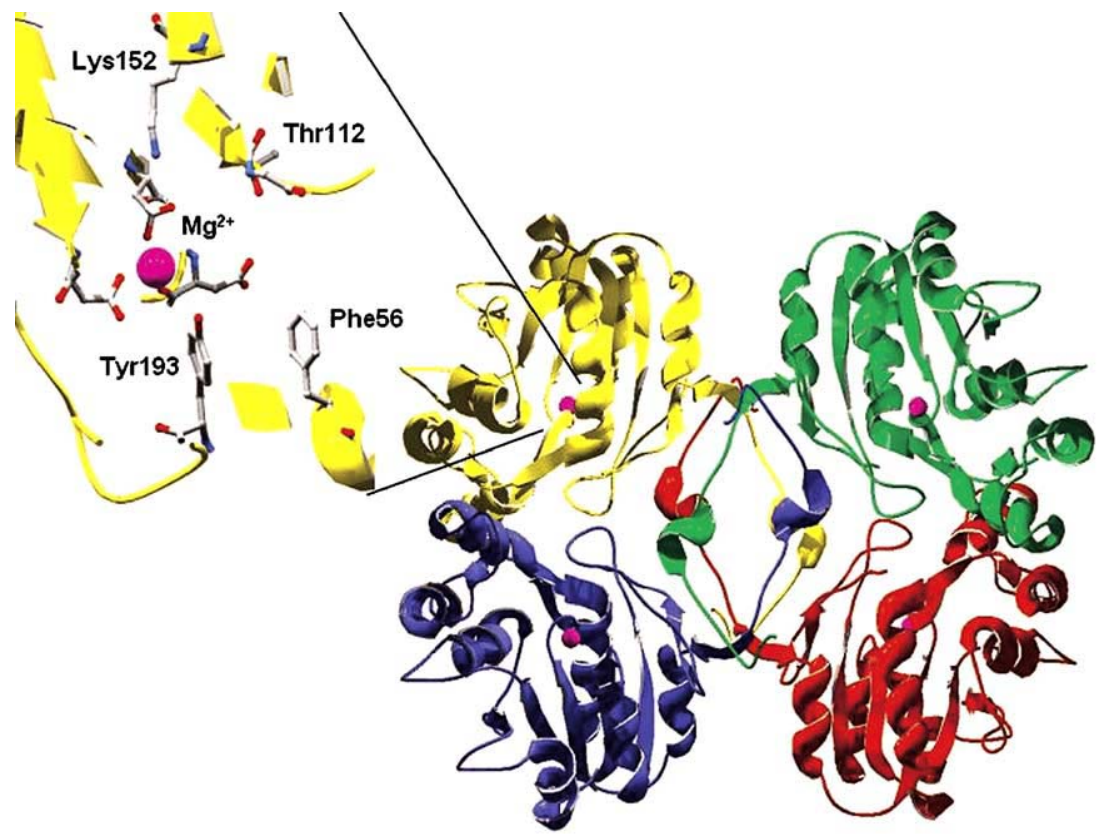

Fig. 1. Ribbon model of the E. coli AphA homotetramer and detail of the residues relevant for substrate binding.

network of H-bonds with the $\mathrm{N} \varepsilon$ of the Lys152, with the backbone $\mathrm{NH}$ atom of Gly113 and finally with the side chain of Asp44. In the second cluster, a comparable interaction of the phosphate moiety was found. The lowest-energy individuals from two clusters differ in the orientation of the pirimidinic ring: in the first cluster the ring lays outside of the lipophylic
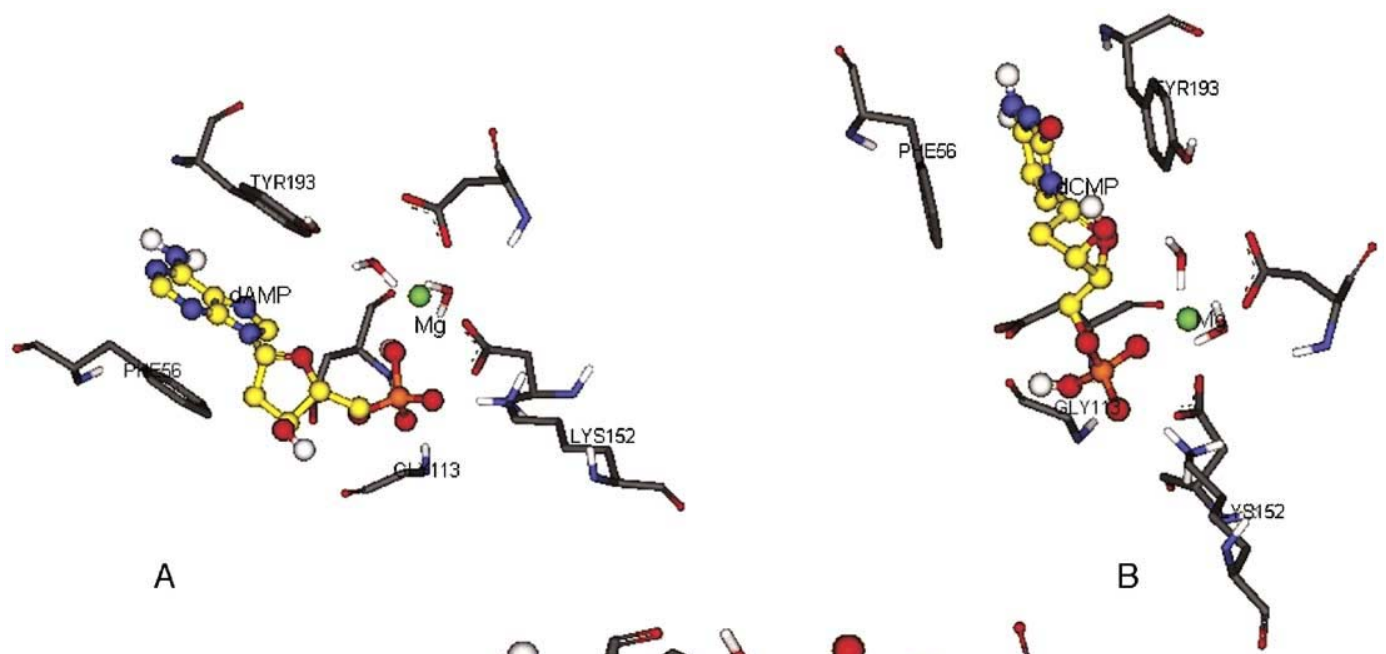

A

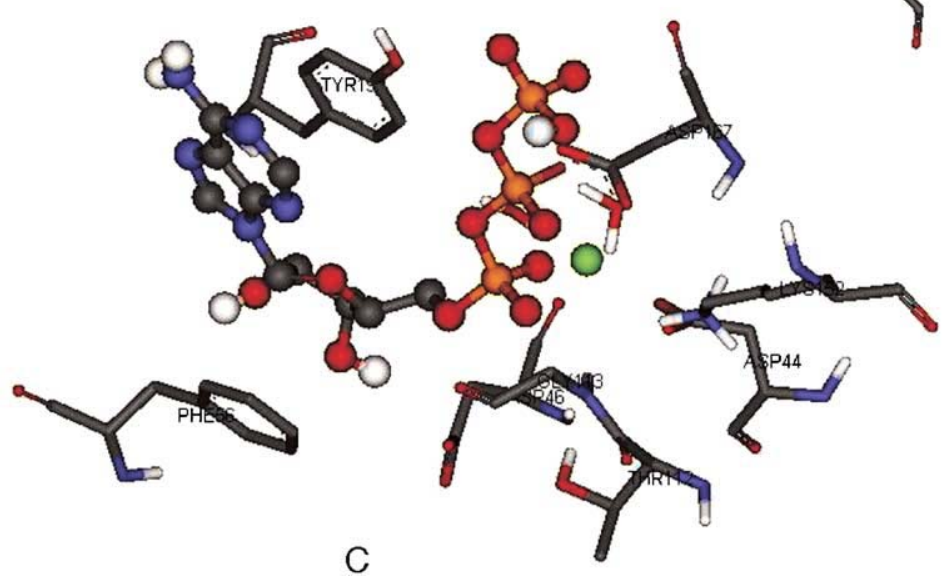

Fig. 2. Models of the minimum energy complexes between AphA and 5' dAMP (section A), 5'-dCMP (section B), and ATP (section C) obtained by the Autodock procedure [11,12]. 
pocket defined by residues Phe56 and Tyr193, The ring amino group is located close to and points toward residues Asp145, Lys72 and Leu71. In the second cluster the pirimidinic ring is located between the aromatic rings of Tyr193 and Phe56, while the ring amino group interacts with the phenolic $\mathrm{OH}$ of residue Tyr70.

AphA-ATP interaction: two high populated low-energy clusters were found. In the lowest-energy cluster an oxygen atom of the $\mathrm{P} 1$ is coordinated to the $\mathrm{Mg}$ (II) atom, but the last two phosphate groups are located outside the active site, close to residues Asp145 and Asn170. In this case, the phosphate moiety is not involved in interactions with residues Lys152 and Gly113. The purine ring of ATP is hosted in the pocket between Phe56 and Tyr193 in (Fig. 2C). The most populated cluster shows a different conformation with the purinic moiety into the liphophylic pocket defined by Phe 56 and Tyr193 while the phosphate tail is displaced from the metal site, located close to residues Leu71, Lys 72 and Asp145.

\section{Discussion}

Kinetic analysis of the AphA enzyme indicated that, although capable of dephosphorylating several different phosphomonoesters, it clearly exhibits a strong preference for $3^{\prime}$ - and (to a somewhat lower extent) for $5^{\prime}$-mononucleotides and monodeoxynucleotides. AphA, therefore can be considered a broad-spectrum nucleotidase highly active against both $3^{\prime}$ - and $5^{\prime}$-mononucleotides and monodeoxynucleotides. These findings would suggest that AphA could play a role in scavenging nucleotides that enter the periplasmic space, to release nucleosides and inorganic phosphate. However, since $E$. coli also produces two periplasmic nucleotidases specific for $3^{\prime}$-nucleotides (CpdB [14]) and 5'nucleotides (UshA [15]), respectively, the physiological significance of AphA in hydrolysis of exogenous nucleotides remains to be clarified.

The kinetic properties of AphA are overall consistent with structural data [3]. In fact, the AphA active site crevice was found to contain a hydrophobic pocket (made by residues Phe56, Leu71, and Trp77 on one side, and Tyr193 on the other) that could easily accommodate an aromatic ring system such as that of nucleotides and could function in positioning the nucleotide substrates in the catalytic site. The modelling of substrate binding to AphA fully supports this hypothesis showing the role of the hydrophobic pocket in docking the purine/pyrimidine ring of nucleotide monophosphates. Indeed, with the exception of one of the $5^{\prime}$-dCMP and 5 -CMP conformers, all the remaining most stable conformers of the substrates always bound AphA with the aromatic moiety stacked between Phe56 and Tyr193 side chains. The docking models also explain the lack of reactivity of the enzyme towards ATP on the simple grounds of the steric requirements for the long ATP phosphate chain to reach the $\mathrm{Mg}(\mathrm{II})$ ion with its terminal $\gamma$-phosphate group. In other words the ATP molecule is simply too long to fit into the enzyme active site cavity. Experimental work aimed at the structural determination of the AphA-substrate complexes will be necessary to confirm the computational hypothesis provided by the modelling analysis.

Interestingly, the active site region of AphA was found to have a significant structural homology with that of human mitochondrial $5^{\prime}-\left(3^{\prime}\right)$ deoxyribonucleotidase [3,5], and the hydrophobic residues that are responsible for the interaction with the aromatic moiety of the nucleotide substrates in the latter enzyme have a counterpart in the above residues of AphA [3]. These structural features are also consistent with the relatively good activity of AphA against $p$ NPP and mononucleotides and could explain the poor affinities observed with different and more hydrophilic molecules such as sugar phosphates or $\beta$-glycerol phosphate.

Recently, biochemical characterization of another bacterial acid phosphatase of the "DDDD" superfamily namely OlpA of Chryseobacterium meningosepticum [16], which belongs to molecular class $\mathrm{C}$, revealed that this enzyme also behaves as a broad-spectrum nucleotidase with a behaviour similar to that of AphA. In fact, both enzymes exhibit a preference for mononucleotides and a similar behaviour with different compounds such as pNPP, Glucose-6-P and $\beta$-Glycerol-P. However unlike OlpA, which exhibits an overall preference for 5'-mononucleotides, AphA shows preference for 3'-mononucleotides, indicating a functional heterogeneity between these two enzymes.

The nature of the metal co-factor present in AphA was not specifically investigated in this work. The greater inhibitory effect observed with EDTA in comparison with chelators that exhibit affinity for zinc (such as dipicolinic acid or 1,10phenanthroline) is consistent with the presence of $\mathrm{Mg}^{2+}$ observed in the previously determined crystal structure [3]. However, since buffers containing $\mathrm{Mg}^{2+}$ were used in the purification steps, we cannot exclude that this could have influenced the metal content of the enzyme. The presence of other divalent cations in the native enzyme and their potential role in enzyme activation, as recently observed for the $E$. coli 5 -nucleotidase [17], will be interesting topics for further investigation of the AphA enzyme.

\section{Acknowledgments}

This work was supported in part by a grant (PAR "Servizi”) from University of Siena. We would like to thank Jean-Denis Docquier for helpful discussions and advice in determining kinetic parameters of the AphA enzyme.

\section{References}

[1] M.C. Thaller, S. Schippa, G.M. Rossolini, Conserved sequence motifs among bacterial, eukaryotic, and archaeal phosphatases that define a new phosphohydrolase superfamily, Protein Sci. 7 (1998) 1647-1652.

[2] M.C. Thaller, S. Schippa, A. Bonci, S. Cresti, G.M. Rossolini, Identification of the gene ( $a p h A)$ encoding the class B acid phosphatase/ phosphotransferase of Escherichia coli MG1655 and characterization of its product, FEMS Microbiol. Lett. 146 (1997) 191-198.

[3] V. Calderone, C. Forleo, M. Benvenuti, M.C. Thaller, G.M. Rossolini, S. Mangani, The first structure of a bacterial class B Acid phosphatase 
reveals further structural heterogeneity among phosphatases of the haloacid dehalogenase fold, J. Mol. Biol. 335 (2004) 761-773.

[4] W. Wang, R. Kim, J. Jancarik, H. Yokota, S.H. Kim, Crystal structure of phosphoserine phosphatase from Methanococcus jannaschii, a hyperthermophile, at 1.8 A resolution, Structure (Camb.) 9 (2001) 65-71.

[5] A. Rinaldo-Matthis, C. Rampazzo, P. Reichard, V. Bianchi, P. Nordlund, Crystal structure of a human mitochondrial deoxyribonucleotidase, Nat. Struct. Biol. 9 (2002) 779-787.

[6] C. Forleo, M. Benvenuti, V. Calderone, S. Schippa, J.D. Docquier, M.C. Thaller, G.M. Rossolini, S. Mangani, Expression, purification, crystallization and preliminary X-ray characterization of the class $\mathrm{B}$ acid phosphatase (AphA) from Escherichia coli, Acta Crystallogr., D Biol. Crystallogr. 59 (2003) 1058-1060.

[7] F. Ausubel, R.E. Kingstone, D.D. Moore, J.G. Seidman, J.A. Smith, K. Struhl, R. Brent, Short Protocols in Molecular Biology, John Wiley and Sons, USA, 1995.

[8] V. Micheli, H.A. Simmonds, M. Bari, G. Pompucci, HPLC determination of oxydized and reduced coenzymes in human erythrocytes, Clin. Chim. Acta 220 (1993) 1-17.

[9] I.H. Segel, Enzyme Kinetics, Behavior and Analysis of Rapid Equilibrium and Steady-State Enzyme Systems, Wiley, New York, 1975, pp. 210-212.

[10] B.N. Ames, Assay of inorganic phosphate, total phosphate and phosphatases, Methods Enzymol. 8 (1966) 115-118.

[11] D.S. Goodsell, G.M. Morris, A.J. Olson, Automated docking of flexible ligands: applications of AutoDock, J. Mol. Recognit. 9 (1996) 1-5.
[12] G.M. Morris, D.S. Goodsell, R.S. Halliday, R. Huey, W.E. Hart, R.K. Belew, A.J. Olson, Automated docking using a Lamarckian genetic algorithm and an empirical binding free energy function, J. Comput. Chem. 19 (1998) 1639-1662.

[13] R. Ragno, A. Mai, S. Massa, I. Cerbara, S. Valente, P. Bottoni, R. Scatena, F. Jesacher, P. Loidl, G. Brosce, 3-(4-Aroyl-1-methyl-1H-pyrrol-2-yl)-Nhydroxy-2-propenamides as a new class of synthetic histone deacetylase inhibitors. 3. Discovery of novel lead compounds through structure-based drug design and docking studies, J. Med. Chem. 47 (2004) 1351-1359.

[14] J. Liu, D.M. Burns, I.R. Beacham, Isolation and sequence analysis of the gene $(c p d B)$ encoding periplasmic $2^{\prime}, 3^{\prime}$-cyclic phosphodiesterase, J. Bacteriol. 165 (1986) 1002-1010.

[15] D.M. Burns, I.R. Beacham, Nucleotide sequence and transcriptional analysis of the E. coli ushA gene, encoding periplasmic UDP-sugar hydrolase (5'-nucleotidase): regulation of the $u s h A$ gene, and the signal sequence of its encoded protein product, Nucleic Acids Res. 14 (1986) 4325-4342.

[16] C. Passariello, S. Schippa, P. Iori, F. Berlutti, M.C. Thaller, G.M. Rossolini, The molecular class $\mathrm{C}$ acid phosphatase of Chryseobacterium meningosepticum $(\mathrm{OlpA})$ is a broad-spectrum nucleotidase with preferential activity on 5'-nucleotides, Biochim. Biophys. Acta 1648 (2003) $203-209$.

[17] L. McMillen, I.R. Beacham, D.M. Burns, Cobalt activation of Escherichia coli $5^{\prime}$-nucleotidase is due to zinc ion displacement at only one of two metal-ion-binding sites, Biochem. J. 372 (2003) 625-630. 